Discussion Paper No. 06-092

\title{
Unemployment Duration in Germany: Individual and Regional Determinants of Local Job Finding, Migration and Subsidized Employment
}

Melanie Arntz and Ralf A. Wilke

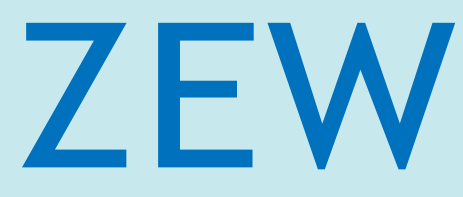

Zentrum für Europäische Wirtschaftsforschung $\mathrm{GmbH}$ Centre for European Economic Research 
Discussion Paper No. 06-092

\title{
Unemployment Duration in Germany: Individual and Regional Determinants of Local Job Finding, Migration and Subsidized Employment
}

\author{
Melanie Arntz and Ralf A. Wilke
}

Download this ZEW Discussion Paper from our ftp server:

ftp://ftp.zew.de/pub/zew-docs/dp/dp06092.pdf

Die Discussion Papers dienen einer möglichst schnellen Verbreitung von neueren Forschungsarbeiten des ZEW. Die Beiträge liegen in alleiniger Verantwortung der Autoren und stellen nicht notwendigerweise die Meinung des ZEW dar.

Discussion Papers are intended to make results of ZEW research promptly available to other economists in order to encourage discussion and suggestions for revisions. The authors are solely responsible for the contents which do not necessarily represent the opinion of the ZEW. 


\section{Non-technical summary}

In the light of high and even rising unemployment levels in Germany, an improved knowledge of how individual characteristics as well as the regional and institutional context shape labor market outcomes of unemployed jobseekers is of central concern to policy makers aiming to design policies that contribute to a shorter average unemployment duration. Recent labor market reforms in Germany aim, among other things, at reducing unemployment by restricting passive unemployment measures, emphasizing local labor market policies and re-structuring public employment services. Empirical evidence regarding the extent to which the regional and institutional context shape labor market outcomes of unemployed jobseekers, however, is quite incomplete. In order to fill this research gap, we explore the main individual, regional as well as institutional determinants of unemployment duration in Germany. For this purpose, we use a rich set of indicators that capture passive and active labor market policies as well as local economic conditions and job counselling activities. Moreover, we distinguish three main exit states each of which are affected quite differently by the regional and institutional context: exits to local regular employment, exits to non-local employment via migration and exits to subsidized employment. By doing so, we provide evidence about the extent to which recent reforms concerning passive labor market measures, regional employment policies and the organization of public employment services are likely to contribute to a reduction of unemployment duration.

We generally obtain that individual characteristics strongly affect the duration of unemployment and the chosen destination state while the effect of local labor market conditions is often rather small. Regional disparities thus appear to be much less important than usually considered by the German public and by German policy makers. Therefore, our results suggest that regional policies may only be a supplementary means of improving labour market outcomes of unemployed individuals. Similarly, there is no evidence that public counselling efforts and active labour market policies have much of an shortening effect on the duration of unemployment. Instead, the results point towards the role of the unemployment compensation and welfare system in shaping individual unemployment experiences. Individuals with low pre-unemployment earnings and thus high income replacement rates have the lowest exit rates to regular employment. This suggests that the reduction of unemployment benefits is likely to drastically shorten unemployment for certain groups. 


\title{
Unemployment Duration in Germany: \\ Individual and Regional Determinants of Local Job Finding, Migration and Subsidized Employment*
}

\author{
Melanie Arntz ${ }^{\dagger}$ \\ Ralf A. Wilke
}

December 2006

\footnotetext{
${ }^{*}$ We would like thank Olaf Schoffer (Statistisches Sachsen) for making the estimations with the Sozialhilfestatistik and Aderonke Osikominu for preparation of the IEBS. We would also like to thank Frederik Schneider, Eva Müller, Philipp Zahn and Stefan Röth for their research assistance and Martina Oertel and Ralf Zimmermann (IAB) for all their help with the IEBS and Guenther Klee (IAW) for the supply of many regional indicators. Comments from Henrik Winterhager, anonymous referees, a co-editor and the participants at numerous seminars are gratefully acknowledged. We gratefully acknowledge the financial support provided by the German Ministry of Labour and Social Affairs through the research project Evaluation of the experimentation clause $\S 6 c$ SGB II (Social Security Code) - comparative evaluation of the success on the labor market of the responsibility models opting municipality (Optierende Kommune) and consortium (ARGE) - research field 1: descriptive analysis and matching. This work uses the Sample of the Integrated Employment Biographies V.1 (IEBS) of the Research Data Centre (Forschungsdatenzentrum) of the Federal Employment Agency (Bundesagentur für Arbeit) at the Institute of Employment Research (Institut für Arbeitsmarkt- und Berufsforschung, IAB). The delivery and the use of the data is in compliance with $\S 75$ SGB X. The IAB does not take any responsibility for the use of its data.

${ }^{\dagger}$ Centre for European Economic Research (ZEW Mannheim), P.O.Box 1034 43, 68034 Mannheim, Germany, E-mail: arntz@zew.de

${ }^{\ddagger}$ University of Leicester, Department of Economics, University Road, Leicester LE17RH, UK, E-mail: raw27@le.ac.uk
} 


\begin{abstract}
Recent labor market reforms in Germany aim, among other things, at reducing unemployment by restricting passive unemployment measures, emphasizing local labor market policies and re-structuring public employment services. This paper uses extensive individual administrative and regional aggregate data to explore the extent to which these factors are likely to contribute to the shortening of unemployment duration. For this purpose, we estimate a semi-parametric duration model with three competing exit states. Our results suggest that changes in the unemployment compensation system rather than local employment policies and administrative restructuring efforts meet expected labor market outcomes. In addition, determinants of the length of unemployment vary across exit states.
\end{abstract}

Keywords: competing-risk, labor market policy, individual and regional data JEL: J64, J61, J68 


\section{Introduction}

Throughout the last two decades Germany has experienced persistently high, and even rising, levels of unemployment. At the same time, the share of long-term unemployed who remain unemployed even after one year of job search has also gone up. According to Machin and Manning (1999), the share of long-term unemployment in Germany was almost 50\% in 1995. This is much higher than in the US, but reflects a labor market situation that is not uncommon in many European countries. In this context, improved knowledge of how individual characteristics as well as the regional and institutional context shape labor market outcomes of unemployed jobseekers is of central concern to policy makers aiming to design policies that will contribute to a shortening of the average unemployment duration. However, most research on the determinants of unemployment duration has been confined to an analysis of individual level determinants (Steiner, 1990; Hunt, 1995; Hujer and Schneider, 1996; Steiner, 2001) and the role of the individual employment histories in determining the duration of unemployment (Lüdemann, Wilke and Zhang, 2006; Fitzenberger and Wilke, 2006b). Passive labour market policies such as unemployment benefit entitlements as a determinant of unemployment duration have also featured prominently in research undertaken in other European countries (e.g. Carling et al. 1996; Roed and Zhang, 2003; Cockx and Dejemeppe, 2005; Lalive, van Ours and Zweimüller, 2006; Kyyrä and Wilke, 2007). Much less attention has been paid to the regional determinants of the unemployment duration. Most studies only test for additional region-specific effects (Folmer and van Dijke, 1988; Brown and Sessions, 1997; Fahrmeir et al., 2003) and conclude that the regional context is a significant determinant of the individual unemployment duration even after controlling for major individual-specific factors. Other studies only assess the impact of the local unemployment rate or the vacancy-to-unemployment ratio as an indicator of local demand deficiency on individual unemployment duration (Lindeboom et al. 1994; Petrongolo 2001; Haurin and Sridhar 2003) and typically find the expected prolonging effect of deficient local labor demand on the duration of unemployment. Both of these approaches remain rather incomplete with respect to improving our understanding of the regional factors that prolong or shorten unemployment. We do not know much either about how the institutional context such as local labor market policies and the organization of local job placement activities affect individual labor market outcomes. This research gap is particularly surprising in the German 
context because, among other things, recent labor market reforms emphasize the role of regionally targeted policy mixes and the organizational structure of public employment services. In particular, German policy makers as well as the public consider a high ratio of job counselers to unemployed jobseekers as a key to reduce the duration of unemployment.

The objective of this study is therefore to conduct a comprehensive analysis of unemployment duration in Germany. We identify the determinants of the length of unemployment not only among individual characteristics, but also consider the regional and institutional context in which individuals seek employment. For this purpose, our analysis uses a rich set of indicators that capture passive and active labor market policies as well as local economic conditions and job counseling activities. Moreover, we use a new generation of German administrative individual data that allows three main exit states to be identified each of which may be affected quite differently by the regional and institutional context: exits to local regular employment, exits to non-local employment via migration and exits to subsidized employment. Previously available data sources did not allow exits to subsidized employment to be distinguished from exits to regular employment. As a consequence, estimated effects of covariates on the duration of unemployment may have been biased if there are heterogenous effects of covariates on different exit types. In the case of subsidized and regular employment, biases are quite likely because labor market programs typically aim at cushioning unfavorable local labor market conditions. Thus, unfavorable labor market conditions may have an opposing effect on exits to regular and subsidized employment. Similarly, a higher migration hazard may be a response to deficient local labor demand that lowers the hazard of finding a local job (Arntz, 2005). The paper thus contributes to the literature by disentangling the relevance of individual, regional and institutional factors for exiting unemployment durations to three important exit states. Since the period covered by our data, 2000-2004, falls mainly into the pre-reform institutional setup, we cannot evaluate the success of recent reform efforts. Instead, our regression type analysis aims at exploring the main individual, regional and institutional determinants of unemployment duration in Germany. By doing so, we provide evidence about the extent to which recent reforms concerning passive labor market measures, regional employment policies and the organization of public employment services are likely to contribute to a reduction of unemployment duration.

Our findings confirm that for both individual and regional covariates, the impact 
differs significantly depending on the type of exit. While deficient local labor demand significantly decreases the likelihood of exiting to regular employment in the local area, the likelihood of migration and the likelihood of entering subsidized employment significantly increases. The estimates indicate, however, that individual-level characteristics have a much stronger impact on the duration of unemployment than regional factors. Thus, regional policies may only be a supplementary means of reducing the duration of unemployment. Similarly, local active labor market programs and a higher provision of counseling resources only marginally affect labor market outcomes of unemployed jobseekers and even yield negative labor market outcomes which would be in line with recent results for the Netherlands (van den Berg and van den Klaauw, 2006). Among the regional and institutional factors, our findings indicate that passive labor market policies may have the strongest impact on the duration of unemployment in Germany. This is suggested by early retirement of individuals with long entitlements to unemployment benefits as well as by major differences in labor market outcomes of unemployed with different income replacement rates.

The structure of our paper is as follows. Section 2 gives a detailed description of the unemployment compensation and welfare system and briefly discusses recent labour market reforms. A third section provides some theoretical underpinning on how job search across multiple labour markets may be affected by regional and institutional factors. Section 4 presents the individual and regional data used in the analysis and discusses the choice of covariates. We then explain the methodological approach before presenting the results in section 6 . Section 7 concludes and discusses the results in light of the recent reforms.

\section{Institutional context in Germany}

Until 2004 the German unemployment compensation system consisted of two main components: unemployment benefits (UB) and unemployment assistance (UA). Unemployment benefits which were paid for a period of up to 32 months, depending on an individual's age and employment history, were equal to $60 \%$ (67\%) of the last net income for unemployed individuals without (with) dependent children. Tax-funded and means-tested unemployment assistance was paid indefinitely to individuals who had exhausted their entitlement to unemployment benefit and continued to provide income replacement rates of $53 \%(57 \%)$ for individuals without (with) dependent 
children. This combination of generous replacement rates for long-term unemployed and indefinite entitlement length was rather exceptional among the OECD countries. As a consequence, replacement rates for long-term unemployed in Germany were and still are higher than in many other OECD countries, especially for older unemployed with extended periods of entitlement to UB and for unemployed with low former earnings who receive complementary tax funded social benefits. This meant that income replacement rates higher than $70 \%$ or even over $100 \%$ were common practice for the latter group. From a search-theoretical perspective, high replacement rates raise reservation wages and thus prolong unemployment as the potential net gain from working compared to not working is small (Mortensen, 1980; Rogerson et al., 2005). The institutional design in Germany thus results in work disincentives that are considered to be partly responsible for the high share of long-term unemployment in Germany and the considerably higher share of long term unemployment among older people (Fitzenberger and Wilke, 2004) and the low wage unemployed (Fitzenberger and Wilke, 2006b). Moreover, the institutional design has also been associated with a lack of jobs for low-skilled workers in Germany as the social benefit level implies a relatively high minimum wage that is above the productivity level of many low-skilled unemployed. The subsequent empirical analysis of unemployment periods between 2000 and 2004 thus draws specific attention to the unemployment experiences of individuals with low earning capacities.

The "Hartz reforms" introduced between 2002 and 2005 ushered in marked changes in active and passive labour market policies. While the Hartz IV reform that merged social benefits and unemployment assistance to create the new social benefit $^{1}$ (Arbeitslosengeld II) was not implemented before 2005 and is thus not relevant for our analysis, the Hartz I-III reforms already started in 2003 (see Jacobi and Kluve (2006) for an extensive overview). These reforms mainly aim at activating the unemployed and increasing the efficiency of employment services and measures. For this purpose, the reform shifts resources from labour market programs aimed at the secondary labour market such as work creation schemes $(A B M)$ to measures that aim at integrating individuals into the regular labour market (e.g. training, subsidies for regular employment and self-employment). In order to improve the efficiency of allocated resources, programs are targeted more strictly to specific groups of un-

\footnotetext{
${ }^{1}$ The ALG II provides almost the same level of benefits as former social benefits, while it is below the UA for individuals with high pre-unemployment earnings. The unemployment insurance based UB was basically left untouched.
} 
employed. After profiling jobseekers according to their chances of finding regular employment, specific reintegration measures are restricted to those who have a fair chance of being reintegrated into the labour market, while work creation schemes are targeted to jobseekers with less promising prospects. In order to activate the unemployed to make as much effort as possible to regain employment, the reforms introduced stricter sanction rules in the case of insufficient search efforts, but also offered a new set of programs such as subsidies for people wishing to set up businesses (Ich- $A G)$ and subsidies for employers hiring individuals with low productivity levels.

Another key objective of the reforms was the restructuring and modernization of the federal employment agency (FEA) in order to increase the effectiveness of its placement services. For this purpose, its regional employment agencies introduced a client-oriented New Customer Service Centre (Kundenzentrum). An entry zone for customer requests and questions in addition to scheduled appointments for job counseling now prevent long waiting times and increases efficiency. Moreover, computer-based assessments now help in analyzing the needs of each customer and thus support tailor-made solutions. These modernization measures also aimed at reducing the workload of each counsellor in order to improve the quality of job counseling. This new emphasis on job counseling has been facilitated by an increase in the number of job placement counsellors since 2002 of almost $30 \%$ and a consequent improvement in the counsellor/customer ratio, i.e. the number of unemployed assisted per placement counsellor.

Another important aspect of the reform concerns the organization of employment services. In contrast to the former hierarchical organization, far greater responsibility has now been assigned to local employment agencies. Each local employment agency now has to achieve stipulated quantitative goals which are tailored to the specific situation of its regional labour market. For such controlling purposes and the design of regionally tailored policy mixes, the federal employment agency asked its research institute, the IAB (Institut für Arbeitsmarkt-und Berufsforschung) to identify employment agencies with comparable regional conditions. The resulting 12 strategic types of employment agencies range from regional employment agencies with unfavourable labour market conditions in eastern Germany to agencies with favourable and dynamic labour market conditions (Blien et al., 2005). The restructuring of the federal employment agency has therefore resulted in an emphasis on job counseling and efficient placement services as well as an emphasis on labour market 
policies which are targeted to the regional labour market. These internal changes of the FEA were mainly executed by leading international consulting companies who received hundred of millions of euros for their input. An empirical analysis of the institutional features is therefore of high policy interest. Since the period covered by our data falls mainly into the pre-reform institutional setup of the FEA, we cannot evaluate the success of the restructuring effort. It is, however, possible to obtain empirical evidence about whether one may expect these changes to bring about a strong reduction in unemployment duration. In this respect, our analysis is aimed at examining the extent to which institutional and regional factors affect the labour market outcomes of jobseekers in Germany once individual factors have been taken into account. For this purpose, we use a broad number of covariates that capture the regional context and some institutional features such as the counsellor/customer ratio. Moreover, we look at exits from unemployment not only to regular but also to subsidized employment and take account of the particularities of the German unemployment compensation and welfare system by distinguishing between groups of different earning capacities.

\section{Some theoretical underpinning}

Before turning to the empirical approach of our analysis, this section briefly discusses how labour market conditions may affect labour market outcomes after unemployment. In this context it is worth considering a framework in which a jobseeker looks for employment in a number of distinct labour markets. In the case of simultaneous job-search across these labour markets ${ }^{2}$, the probability of exiting to any of those labour markets can be broken down into the job offer probability and the probability of accepting a job offer in this labour market, both of which depend on exogenous market conditions and the endogenous search strategy adopted by the unemployed job searcher. In particular, jobseekers choose reservation wages for each of the distinct markets such that the value of employment at the offered wage is equivalent to the value of continuing the unemployed job search. Moreover, search effort is allocated across the markets so that the marginal value of additional search in each market is equal to the marginal cost of searching the market. While reservation

\footnotetext{
${ }^{2}$ Alternatively, one may assume some sort of sequential search strategy (Salop, 1973; McCall and McCall, 1987). Accordingly, an unemployed job seeker searches sequentially according to the expected returns from searching a particular market segment.
} 
wages affect job acceptance probability, the allocation of search effort across distinct markets influences the job offer probability. Intuitively, an individual's search strategy should favor finding employment in those labour markets that offer the best work conditions. In the case of job search across multiple industries, Fallick (1992) has shown that improving conditions in one labour market - i.e. increasing job offer probability - raises reservation wages in all markets while at the same time shifting search effort towards the improving market and reducing search effort in all others. As a consequence, changing exogenous conditions affect the hazard of exiting to a specific market not only directly due to, for example, higher job offer probabilities, but also affect these hazards indirectly via the endogenous search strategy of the unemployed job searcher. A similar notion has also been applied to job-search across sectors (Thomas, 1998) and regions (Damm and Rosholm, 2003; Arntz, 2005).

In our framework, we allow for a local and a non-local labour market and introduce a labour market for subsidized jobs. Exits to non-local employment are likely to constitute only a relatively small but still noticeable share of all exits as migration levels in Germany are low compared with the US, Australia and Canada, but among the highest compared with other European countries (OECD, 2005). We refer to subsidized jobs whenever an individual exits to employment in the context of an active labour market program. Such programs mainly encompass subsidized jobs in the secondary labour market, subsidies for regular employment and subsidies for self-employment (see data section for details). The reforms of recent years have brought about a shift from subsidized jobs in the secondary labour market to the latter two program types (BA, 2004). In 2002, more than 200,000 jobseekers entered subsidized jobs in the secondary labour market and more than 350,000 jobseekers received a subsidy for regular employment or self-employment (BA, 2002). Compared with other European countries, subsidized employment in Germany is an important part of labour market policy. While spending on active labour market policies in Germany has been around average compared with other European countries, the proportion spent on subsidized employment has been above average in recent years (Martin and Grubb, 2001). Exits to subsidized employment are thus likely to constitute a substantial part of all exits from unemployment.

Applying the above job search framework across multiple labour markets to our particular setting, jobseekers are simultaneously looking for employment in the market for regular ${ }^{3}$ local, regular non-local and subsidized employment. Thus, jobseekers

\footnotetext{
${ }^{3}$ Regular employment can be further differentiated by the number of hours worked or the type
} 
choose the search strategy, i.e. reservation wages and the search effort for each of these markets according to the attractiveness of each of these markets in terms of job availability, offered wages and work conditions. In many cases, labour market conditions that favor an exit to local regular employment may have an opposing effect on non-local exits (Arntz, 2005). Similarly, subsidized employment is often a means of cushioning unfavourable local labour market conditions. Distinguishing between these three exit states should therefore be quite helpful in understanding how the regional and institutional context affects labour market outcomes of jobseekers in Germany. For this purpose, the empirical analysis considers a number of indicators that capture the exogenous conditions of the local labour market that are discussed in detail in the next section. By affecting the search strategy, such conditions not only affect the duration of unemployment, they also affect the probability of making a transition to either local employment, non-local employment or subsidized employment. Other behaviorally distinct and alternative destination states after unemployment that, due to data limitations, are not considered here include exits to self-employment or out of the labour force entirely. Our analysis should therefore be considered as a starting point for improving our understanding of the impact of labour market conditions on the labour market outcomes of unemployment.

\section{Data}

This section describes how we select the sample and covariates for our analysis. We use individual data merged from several administrative registers which is then combined with regional data from various sources.

Individual data The Sample of the Integrated Employment Biographies V.1 (IEBS) of the Research Data Centre (Forschungsdatenzentrum) of the FEA is a new data set which was released in 2005. See Hummel et al. (2005) for a detailed description of the data. It is a $2.2 \%$ sample containing about 1.4 million individuals in the period 1992-2004. It comprises high quality information about employment periods that have been subject to social insurance payments and thus excludes civil servants and self-employed individuals. The sample also contains information on the receipt of unemployment compensation from the FEA. For the period 2000-2004,

of job contract (temporary versus unlimited). However, the data we use does not contain the relevant information such that we pool all types of regular employment 
the data set also provides information about participation in active labour market programs. One of the major drawbacks of the data is that it only partially identifies the true unemployment period. This is because there are unobserved periods in the employment trajectories whenever an individual is neither a socially insured employee nor receives unemployment compensation, nor participates in any active labour market program. As a consequence, some parts of the individual employment trajectory may not be observed so that various proxies for the true unemployment period can be computed based on different criteria which define the labour market status of being unemployed, see e.g. Fitzenberger and Wilke (2004) and Lee and Wilke (2005) for this problem. In the analysis of this paper we use the following proxy for the true unemployment duration:

- Unemployment with permanent income transfers (UPIT) is a lower bound of the true unemployment period that defines unemployment as a continued period of transfer receipt. Gaps between transfer receipt and the beginning of a new employment period need to be less than four weeks. Thus, UPIT excludes periods of unemployment without receipt of UB or UA from the FEA.

Unfortunately, there is no exact way of telling whether this unemployment proxy more closely resembles the true length of unemployment than competing proxies. As discussed in the second section, our analysis is aimed at examining determinants of the length of unemployment specifically for unemployed social benefits recipients because this labour market segment is likely to experience particularly long unemployment periods and different exit states compared with individuals with higher earning capacities. Comparisons of unemployment periods of social benefits recipients which are contained in the Social Benefits Statistics (Sozialhilfestatistik, SHStat) with unemployment spells in the IEBS defined according to the above definition and a wider proxy which also adds nonemployment periods to the unemployment duration suggest that the UPIT definition better represents unemployment spells of unemployed social benefit recipients. ${ }^{4}$ Moreover, the UPIT proxy for individuals

\footnotetext{
${ }^{4}$ The use of the SHStat was confined to the research project Evaluation of the experimentation clause $\S 6 c$ SGB II which was funded by the German Ministry of Labour and Social Affairs. No scientific use file exists for this unique data set such that apart from the comparison of both data sets, no further analysis could be conducted. For more details on the comparison of the data sets see Arntz et al. (2006).
} 
on pre-unemployment gross earnings of less than 60 euros per day turned out to be the most suitable to represent the group of unemployed social benefit recipients. A daily gross wage of 60 euros closely corresponds to the lowest wage quintile for full-time employees in western Germany and to the lowest two wage quintiles for full-time employees in eastern Germany. Since the legal minimum standard of living is somewhat lower in eastern Germany, applying the same threshold for both parts of Germany may be somewhat crude. Robustness checks using, for example, unemployed in the lowest wage quintile for both parts of Germany, did not significantly change the results. Based on these robustness checks and the comparison with unemployment periods of social benefits recipients in the SHStat, we therefore decided to apply the UPIT definition in the subsequent empirical analysis and stick to the chosen threshold of 60 euros daily gross earnings to distinguish individuals of low-earning capacities from individuals with higher earning capacities. Individuals above this threshold are less likely to receive additional social benefits and should thus have different unemployment experiences than their low-wage counterparts.

For all UPIT unemployment spells, we observe the exit state if the spell is not right-censored due to the end of the observation period and if the unemployed continuously receives income transfers from the FEA. As discussed in the theoretical section, we distinguish between local regular employment, non-local regular employment (migration) and subsidized employment. We define migration as movements between non-adjacent labour market regions (Arbeitsmarktregionen). The 227 labour market regions (LMRs) in Germany comprise typical daily commuting ranges such that for the majority of individuals the workplace is located within the LMR. Finding employment in a non-adjacent LMR therefore usually necessitates residential mobility. We refer to subsidized employment whenever an individual exits to socially insured employment or self-employment in the context of an active labour market program. Such programs mainly encompass subsidized jobs in the secondary labour market $(A B M, S A M)$, subsidies for regular employment (Eingliederungszuschüsse, Beschäftigungshilfen) and subsidies for self-employment (Ich-AG, Überbrückungsgeld), but also contain more extensive training programs $(F b W)$ if these programs count as socially insured employment. Table 1 describes the composition of all exits to subsidized employment observed in the IEBS for UPIT spells starting between 2000 and 2002. For the analysis, we decided to pool all forms of subsidized employment because robustness checks for distinguishing between certain types of programs did not yield noteworthy differences compared to 
pooling all programs.

Table 1: Composition of exits to subsidized employment, IEBS, 2000-2002

\begin{tabular}{lll}
\hline \hline Subsidy for ... & Number & $\%$ \\
\hline$\ldots$ employment in secondary market & 10,391 & 31.0 \\
$\ldots$. regular employment & 9,643 & 28.7 \\
$\ldots$ self-employment & 9,001 & 26.8 \\
$\ldots$ training measure & 2,146 & 6.4 \\
$\ldots$ other programs & \\
\hline Total subsidized employment & 2,379 & 7.1 \\
\hline \hline \multirow{2}{*}{ This category refers to a mix of programs that can be autonomously designed by each em- } \\
\multicolumn{2}{c}{ ployment agency. As an example, these measures include subsidies for entering vocational } \\
training or a premium for extending working hours of an existing job (BA, 2002).
\end{tabular}

We restrict our analysis to unemployment periods starting in the period 20002002. This is because information on periods of subsidized employment is not available before 2000. Since we are able to observe information about unemployment up to 2004 while exits to employment are only observable up to the end of 2003 , we decided to exclude spells starting in 2003. This reduces the amount of right censoring in the data and ensures a minimum observation period of one year. Table 2 shows the sample sizes and exit types when applying the UPIT definition and distinguishing individuals by their earning capacities. We also distinguish by gender and marital status as these characteristics are important determinants of individual labour market outcomes.

Table 2 shows that individuals with low pre-unemployment wages are more likely to exit to subsidized employment and less likely to migrate than jobseekers with higher pre-unemployment earnings. Moreover, the median unemployment duration is significantly longer for low wage earners, a finding that is in line with the expectations that the institutional framework creates disincentives for individuals with low earning capacities to take up a job. 
Table 2: Unemployment duration and exit types by gender, marital status and earning capacity, IEBS, 2000-2002

\begin{tabular}{lllll}
\hline \hline & \multicolumn{2}{c}{ Low Wage } & \multicolumn{2}{c}{ Higher wage $^{\mathrm{a}}$} \\
& Men & Women & Men & Women \\
\hline Singles & & & & \\
\% exit to & & & & \\
local employment & $48.1(70.3)$ & $51.3(74.0)$ & $57.9(74.5)$ & $53.5(70.5)$ \\
non-local employment & $6.4(9.4)$ & $5.6(8.1)$ & $9.1(11.7)$ & $10.3(13.6)$ \\
subsidized employment & $13.9(20.3)$ & $12.4(17.9)$ & $10.7(13.8)$ & $12.1(15.9)$ \\
all exits & $68.4(100.0)$ & $69.3(100.0)$ & $77.7(100.0)$ & $75.9(100.0)$ \\
Unemployment spells & & & & \\
Median duration (days) & 138 & 146 & 107 & 123 \\
Number of spells & 43,528 & 31,206 & 20,849 & 7,319 \\
\hline \hline Married & & & & \\
\% exit to & & & & \\
local employment & $47.5(64.9)$ & $44.6(60.9)$ & $58.7(73.3)$ & $45.9(72.6)$ \\
non-local employment & $5.8(7.9)$ & $2.8(3.4)$ & $8.0(10.0)$ & $4.6(7.3)$ \\
subsidized employment & $19.9(27.2)$ & $14.7(20.1)$ & $13.4(16.7)$ & $12.7(20.1)$ \\
all exits & $73.2(100.0)$ & $62.1(100.0)$ & $80.1(100.0)$ & $63.2(100.0)$ \\
Unemployment spells & & & & \\
Median duration (days) & 176 & 238 & 116 & 194 \\
Number of spells & 28,018 & 31,088 & 23,620 & 5,483 \\
\hline \hline
\end{tabular}

${ }^{a}$ Low wages refers to individuals with pre-unemployment daily gross wages of less than 60 euros, while higher wages denote pre-unemployment earnings above this threshold.

Table 2 also indicates differences by gender and marital status. Singles are geographically more mobile than their married counterparts, a finding that is consistent with the migration literature regarding higher migration costs for married people with children (see Ghatak et al., 1996). Differences between female and male singles, however, are very small. Since estimation results for single males and females proved to be very similar, we decided to pool male and female singles in the subsequent analysis. By contrast, results for married individuals strongly differ by gender. Married women have by far the longest median unemployment duration and the lowest exit rates. This probably reflects the looser labour force attachment of married women. 
Moreover, the extremely low migration rates among married women may reflect the fact that women are more likely to be tied to the local area if the male breadwinner is employed locally. Due to these particularities of labour market decision of married women, we decided to restrict the analysis to married males and single people only and differentiate these groups by their earning capacities. Individual-level covariates for the econometric analysis that are contained in the IEBS are age, education and a number of indicators of an individual's employment history such as previous unemployment, previous participation in active labour market programs and previous commuting status. These covariates are chosen to capture differences in job-finding chances and migration cost that are relevant for the labour market outcomes of jobseekers. Summary statistics of the samples used in the subsequent duration analysis can be found in Appendix A.

Regional aggregate data We use a broad number of regional indicators which are mainly provided by the two largest German data producers: the Federal Employment Agency and the Federal Statistical Office (FSO). The FEA data is coded at the level of employment agency districts and contains information about labour market tightness (e.g. vacancies, jobseekers, degree of long term unemployment), the extent and structure of local labour market programs and the organization of the local employment agency (e.g. number of staff). The FSO data contains county level information about the population structure (e.g. age, education), the type of region (urban vs. rural), its infrastructure and industrial structure. There are 180 employment agency districts and 440 counties in Germany, the exact delineation of which are shown in Arntz and Wilke (2007). We decided not to aggregate the regional data to labour market regions because for some indicators we only have spatially intensive data such as percentages that cannot be easily aggregated.

The FSO and the FEA data provided us with more than 100 regional indicators, a full list of which is included in Arntz et al. (2006). For the purposes of econometric analysis, there are far too many regional covariates as there is a high degree of correlation among several of these regional indicators. Thus, as a first step we used a combination of cluster and factor analysis to identify indicators that contain very similar information. In a next step, we decided to compress the regional information further by grouping the remaining regional indicators according to economically reasonable groups that cover major regional factors that are likely to affect unemployment durations and the labour market state after unemployment as discussed 
in the theoretical framework. In particular, we create five groups and select up to five indicators as their representatives such that the correlation among the representatives is minimized. As a consequence, the chosen representatives proxy for their group of interest in the econometric analysis so that estimated coefficients reflect effects of the group they represent. Table 3 shows a description and summary statistics of all regional indicators. There is a large regional variation in most of the indicators that describe the regional labour market situation. In fact, regional disparities in unemployment rates, for example, are among the largest in Europe (OECD, 2005). Thus, there should be enough regional variation to identify the effect of regional covariates on labour market outcomes. For the subsequent econometric analysis, we standardized all continuous regional variables to ease comparability of estimation results.

The first group of indicators characterizes local labour demand and supply conditions, i.e. local job availability. The local unemployment rate may be considered as an indicator of deficient local labour demand. In addition, the change in the unemployment rate compared to the previous year conveys information about the development of the local imbalance of labour supply and demand. In regions with an excess supply of labour, the probability of receiving a job-offer should be reduced. As a reaction, reservation wages in all labour markets decrease since jobseekers become less choosy and search effort shifts from the local to alternative markets. This implies a decrease in the number of local jobs found and an increasing hazard of finding a non-local or a subsidized job. An excess supply of labour may also increase the availability of subsidized employment because corresponding labour market programs are often used to cushion unfavourable labour market conditions.

Another important determinant of unemployment duration might be local economic performance since well-performing and dynamic regions should offer a higher expected lifetime income and should thus attract search effort to the local market while non-local and subsidized employment should become less attractive. Well-performing and economically growing regions should be characterized by a high and growing GDP per head as well as by a high level of newly established businesses. The analysis thus includes corresponding indicators. 


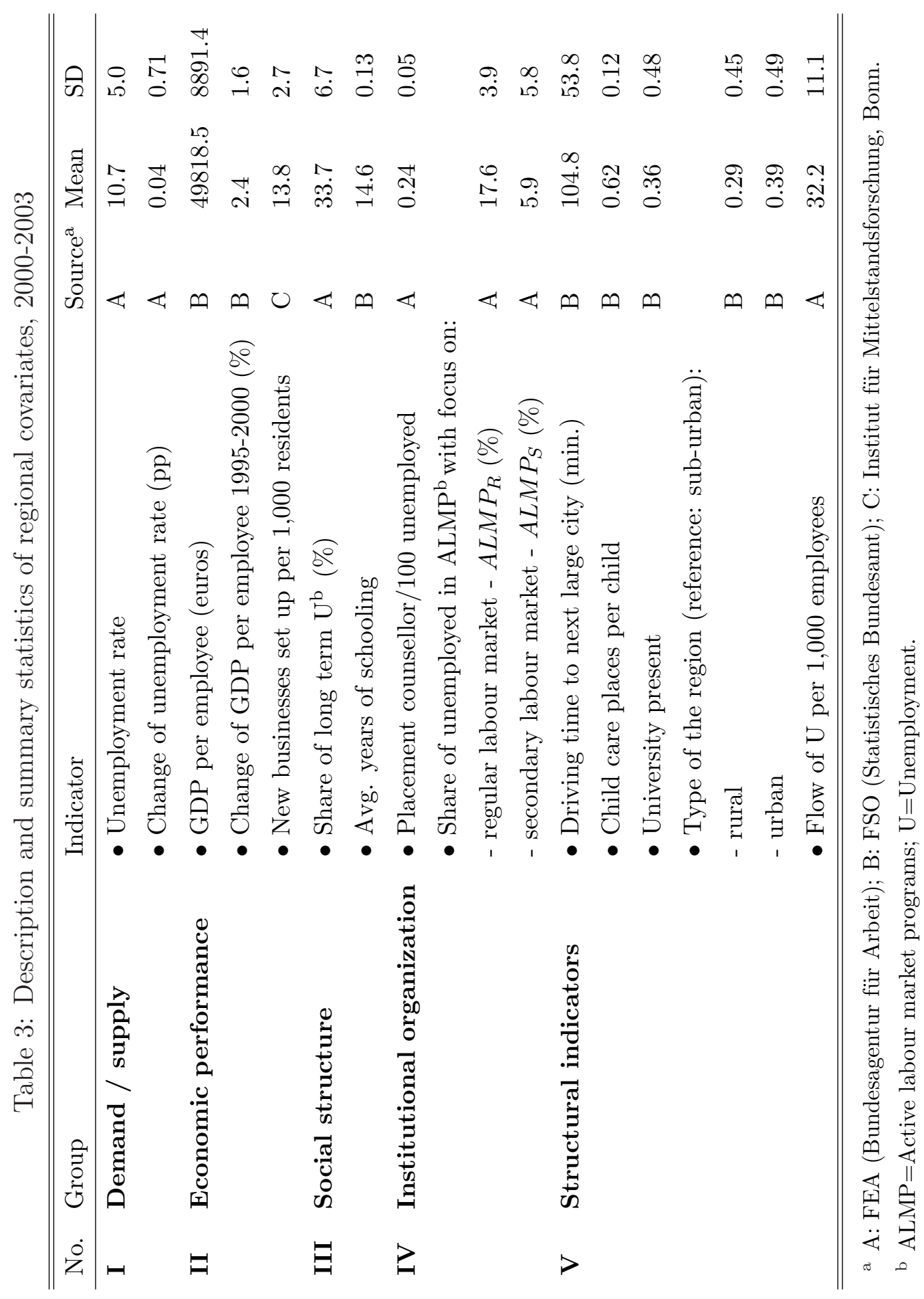


Apart from the economic conditions of the locality, its social structure may also shape individual labour market behavior. In particular, individuals may have "lower incentives to work where peers are also unemployed ... and a view of joblessness as unproblematic within a context of lowered aspirations, ..." (Ritchie et al., 2005:3). In Germany, discouraging social contexts might be found in old industrial regions which have experienced massive deindustrialization in recent decades and a subsequent rise in long-term unemployment. We thus decided to include indicators such as the level of long-term unemployment and the average schooling level in the region to control for different social contexts. If such contexts lower work incentives, exiting to any kind of employment may be less likely.

In addition, we use information about the institutional organization of the local employment agency. As discussed in section 2, there has been an increase in the number of job placement counsellors of around $30 \%$ during the period of observations. This politically motivated increase in the counsellor/customer ratio, i.e. the ratio between placement officers per jobseeker, provides some variation to identify the effect of an increasing level of job counseling. We hypothesize that a higher counsellor/customer ratio positively affects both local and the non-local jobfinding probability, but that exits to subsidized employment might be reduced if subsidized employment to some extent substitutes for job counseling. We also include indicators of the local availability of labour market programs. As discussed in section 2, there have been changes in the structure of labour market programs with a shift from measures aiming at the secondary labour market to programs that aim at integrating individuals into the regular labour market. We therefore include the share of unemployed participating in programs with a focus on the regular labour market such as training measures $(F b W)$, programs targeted to young unemployed $(J U M P))$ and subsidies for regular employment or self-employment(Übergangsgeld, Eingliederungszuschuss, Beschäftigungshilfe) and also include the share of unemployed participating in programs with a focus on the secondary market such as work creation schemes $(A B M, S A M) .{ }^{5}$ While exits to subsidized employment should be positively affected by the level of offered programs, the hazard of leaving the region may be negatively affected. This regional locking-in effect of active labour market policies has been discussed in the Scandinavian literature (e.g. Westerlund, 1998; Fredriksson, 1999). Accordingly, a high level of local program activities may offer a

\footnotetext{
${ }^{5}$ Further differentiating the program types is problematic as we often found a high degree of correlation between similar program types.
} 
substitute to departure from the region so that the search strategy of the unemployed job searcher rather favors entering subsidized employment.

Finally, we include several structural indicators to characterize the type of region. In particular, we include a population density related classification to distinguish between rural and urban regions. Moreover, we use driving distance to the next higher level city as a proxy for the degree of remoteness of a region. Both of these characteristics affect the availability and the accessibility of employment and may thus change an individual's search behavior. We also control for three other regional characteristics. Regions with a high level of seasonal work, proxied for by the flow in and out of unemployment, may be characterized by a large share of short unemployment spells. Secondly, the local existence of third level institutions may affect the composition of the available workforce. The availability of a highly flexible workforce such as students may affect the competition for certain jobs and thus affect the flow out of unemployment. Finally, we include the local availability of child care support in order to test whether the public infrastructure affects unemployment experiences of jobseekers with children. The availability of kindergarten or nursery school might reduce the opportunity cost of local employment and thus accelerate exits to local employment.

\section{Methodological issues}

Let $F(t)$ be the unemployment duration distribution, where $t$ is the duration of unemployment. The hazard rate, $h(t)=\{\partial F(t) / \partial t\} /(1-F(t))$, is an intuitive way of formalizing transitions from unemployment to employment. In our econometric analysis we use a hazard rate model to investigate the effect of various covariates $x=$ $\left\{x_{1}, x_{2}\right\}$ on the distribution of unemployment, where $x_{1}$ denotes the set of individual characteristics such as demographics, socio-economics, work history variables and firm-level variables, while $x_{2}$ contains all remaining regional indicators. In particular, we estimate a competing-risk Cox-proportional hazard model

$$
h_{j}(t \mid x)=\lambda_{j}(t) \exp \left(\alpha_{j} x_{1}+\beta_{j} x_{2}\right)
$$

where $j$ denotes the exits to local regular employment, subsidized employment and non-local employment, i.e. migration, and $\lambda_{j}$ is the destination specific baseline hazard rate. 
There are three major sources of biases that have to be addressed when using this approach. First of all, there may be biases from unobserved individual heterogeneity. As suggested by Meyer (1990), however, unobserved individual heterogeneity may not have much of an effect if there is a flexible baseline hazard that partly absorbs this heterogeneity. Secondly, there may be a simultaneity issue of the regional covariates if an exit directly affects the covariates used in the analysis. This may be the case if an exit to local employment reduces the unemployment rate or if an exit to subsidized employment increases the offer rate for active labour market programs. For this reason, all regional covariates have been calculated as the average value for the 12 months preceding the start of unemployment. Estimation results may, however, still be biased if regional characteristics that are correlated to the observed covariates are omitted. In the literature, this problem has been addressed by stratification (see Ridder and Tunali, 1990). When stratifying according to regional labour markets, separate baseline hazards are estimated for each regional labour market. This approach resembles the well-known fixed effects approach and thus controls for unobserved heterogeneity at the level of regional labour markets. Unfortunately, our data is limited to a relatively short time span. Thus, a stratified estimation approach turns out to be infeasible since, in this case, identification rests on time variation. We are nonetheless fairly confident that biases from omitted regional characteristics may be negligible due to the rich account of regional covariates used in the analysis.

As has been discussed by Thomas (1996), in a competing-risk duration analysis, the estimated parameter vector $\left(\alpha_{j}, \beta_{j}\right)$ may not be interpreted as the effect on the duration until exit to state $j$. Instead, the effect on this duration depends on parameter vectors for all states. In particular, define the conditional cumulative probability of exiting to state $\mathrm{j}$ until $\mathrm{t}$ as

$$
\Pi_{j}(t \mid x)=\int_{0}^{t} h_{j}(t \mid x)(1-G(t \mid x)) d t
$$

with $h_{j}(s)$ as the exit hazard to state $\mathrm{j}$ and $(1-G(s))$ as the overall survival probability that takes account of all exit options. In our empirical analysis we evaluate the estimates at $x_{l} \in\left\{\bar{x}_{l}, 0\right\}$, where we choose the average values of all individual level variables $\left(x_{1}=\bar{x}_{1}\right)$ and we choose zero for the regional variables $\left(x_{2}=0\right)$. ${ }^{6}$ We estimate the probability of exiting to state $\mathrm{j}$ as the duration elapses one year, i.e.

\footnotetext{
${ }^{6}$ This corresponds to the sample mean value of the continuous regional variables and to the reference category of the regional dummy variables.
} 
$\Pi_{j}(365 \mid x)$. We compute the marginal effects $\partial \Pi_{j}(365 \mid x) / \partial x_{k}$ as the marginal change of the cumulative probability of exiting to state $\mathrm{j}$ during the first year if one regressor $x_{k}$ changes. This outcome is of particular political interest because long-term unemployment starts after one year of unemployment. Thus, our marginal effects correspond to the change in probability of becoming long-term unemployed that is due to a marginal increase of covariate $k{ }^{7}$ Based on 500 samples, we estimate the standard error of the conditional marginal effect bootstrap distribution. Assuming that standard errors are distributed normally, we then determine the significance level of the estimated marginal effects.

\section{Results}

Tables 4 and 5 present the estimated conditional marginal effects for single people and married men of low and higher earning capacities. We generally find that the individual work-history seems to be the driving force behind the duration of unemployment, a result that is similar to Lüdemann et al. (2006) and Fitzenberger and Wilke (2006b) who use data without information on subsidized employment and on migration. Our results also indicate some convergence of the conditional distribution of unemployment duration in western and eastern Germany during the years 2000-2004. Compared to the impact of individual characteristics, regional disparities only marginally affect the length of unemployment periods in Germany as has also been suggested by Arntz (2005) who uses data without information on subsidized employment. Thus, although some regional factors significantly affect both the unemployment duration and the likelihood of ending up in a specific destination state, our results suggest that the recent emphasis on regional policies, regionally tailored policy mixes and the organization of public employment services is unlikely to bring about a substantial reduction in the length of unemployment in Germany. Rather, there is some evidence that certain regional policies such as the local provision of

\footnotetext{
${ }^{7}$ Since $\Pi_{j}(t \mid x)$ has the properties of a distribution function, one may define the conditional marginal quantile effect at quantile $\mathrm{q}$ as $\partial \hat{t}_{j}(q \mid x) / \partial x_{k}=\partial \Pi_{j}^{-1}(q \mid x) / \partial x_{k}$ as an alternative marginal effect. Since the underlying unemployment duration distribution is defective, $\Pi_{j}^{-1}(q \mid x)$ does not exist for the upper quantiles so that $0 \leq \Pi_{j}(t \mid x) \leq \bar{q}_{\mid x} \leq 1$. Moreover, the maximum quantile for which this marginal effect can be identified varies by covariate and destination state, i.e. $\bar{q}_{j k}$. For this reason, we decided to report the marginal effect on the cumulative probability $\Pi_{j}(365 \mid x)$ only. Marginal quantile effects are available from the authors upon request.
} 
active labour market programs may even yield negative labour market outcomes. In what follows we present a detailed discussion of the estimation results for the individual-specific covariates before turning to the regional covariates. In line with the finding that regional covariates have only a limited impact on individual labour market outcomes, we also find only few general and robust result patterns across the four sub-groups. A detailed discussion of each single effect thus seems an infeasible approach for the regional covariates. Instead, we only focus on the most important results for each group of regional covariates and point to the most interesting and robust differences across the sub-samples.

Socio-demographics Several socio-economic variables significantly affect the duration of unemployment ${ }^{8}$, but only few of them have a strong effect. Among the most important for all exit states of single people and married men alike is age. Generally, the older unemployed, especially those aged 56 or older, are less likely to take up regular employment locally, are less likely to migrate and are more likely to end up in subsidized employment. Among unemployed people with higher earning capacities, the older unemployed are only less likely to exit to local regular employment. We can also confirm the results of earlier studies with regard to educational attainments: a higher educational degree does not improve the likelihood of local regular employment. Instead, unemployed people with a university degree are more likely to enter subsidized employment and they are much more likely to migrate if they are single. Among married men with a university degree, lower exit probabilities to local regular employment are only partly compensated for by higher exit probabilities to subsidized employment. Interestingly, married men with a university degree are not significantly more mobile than their less educated counterparts. The lower earning capacities associated with higher income replacement rates rather than the observed educational degree are thus able to explain the high share of long term unemployment among the unskilled in Germany. This also confirms our approach in this paper to stratifying the sample with respect to the wage level.

Work history variables These characteristics have the strongest influence on the unemployment duration distribution and effects are typically similar for all samples. In particular, long entitlement periods for unemployment benefits (UB) and former

\footnotetext{
${ }^{8}$ When the effect is similar for all destinations we simply use the notion unemployment or unemployment duration.
} 
employment subsidies by the federal employment agency strongly decrease the likelihood of local regular employment. Our results therefore suggest that both passive and active labour market measures are strongly associated with negative individual labour market outcomes. We do not, however, read this as a causal relationship, as these results may partially be driven by unobserved factors such as a negative selection of unemployed into subsidized employment. In the case of very long entitlement periods ( $>24$ months) any destination is much less likely because this form of unemployment is associated with early retirement such that this group of unemployed rarely looks for a new job. This effect is typically observed for very long entitlement periods and it is more pronounced among unemployed with higher former wages. We also obtain strong result patterns if an unemployed person was already subsidized by the local employment office at the end of his last unemployment period or just before the start of the current unemployment period. If these individuals slip back into unemployment they have a very low transition probability to either local or non-local regular employment. Instead, a high percentage of these individuals ends up in another subsidized employment period. We are therefore able to identify what is typically called a "career of labour market measures". 9 Using the newer generation of individual administrative data we are now able to identify this important determinant.

Furthermore, we do not observe a stigmatizing effect of former unemployment periods in the sense that it increases unemployment duration. This is in line with several former studies based on administrative data. We also identify several factors that increase exit probabilities among the unemployed. Individuals who have previously been recalled by their former employer, have much shorter unemployment periods due to faster local exits. Moreover, this group is less likely to be subsidized or to migrate, and this suggests that recalls are related to seasonal unemployment and temporary lay-offs. Being in minor employment ${ }^{10}$ at the beginning of the unemployment period considerably increases local job finding and reduces the likelihood of migration in many cases.

\footnotetext{
${ }^{9} \mathrm{We}$ also made estimations in which we distinguished between several types of employment subsidies offered by the employment agencies. Surprisingly, the results patterns are similar even for subsidized artificial jobs and temporary subsidies of regular employment which have a very purpose. For this we decided to report the pooled results only.

${ }^{10}$ An employment on a salary of less than 400 euros per month and with exemption from social security contributions.
} 
Table 4: Marginal effects in pp on the conditional cumulative probability of exiting to local, subsidized or nonlocal employment, Singles

\begin{tabular}{|c|c|c|c|c|c|c|}
\hline \multirow[b]{2}{*}{ Variable } & \multicolumn{3}{|c|}{ Low wage } & \multicolumn{3}{|c|}{ Higher wage } \\
\hline & local & subsidized & non-local & local & subsidized & non-local \\
\hline \multicolumn{7}{|l|}{ Individual characteristics } \\
\hline Female & $7.6^{* *}$ & $-0.8^{\dagger}$ & $0.6^{\dagger}$ & $2.9^{*}$ & -0.5 & $2.1^{* *}$ \\
\hline Age $<26$ & $16.7^{* *}$ & $-0.9^{* *}$ & $1.2^{* *}$ & $11.7^{* *}$ & $-2.2^{* *}$ & 0.0 \\
\hline Age 26-35 & $3.7^{* *}$ & $0.4^{\dagger}$ & $1.1^{* *}$ & $4.2^{* *}$ & $0.7^{\dagger}$ & $1.0^{* *}$ \\
\hline Age 46-56 & $-9.6^{* *}$ & $1.5^{* *}$ & $-0.9^{* *}$ & $-4.5^{* *}$ & 0.2 & -0.2 \\
\hline Age $>56$ & $-22.2^{* *}$ & -0.8 & $-1.7^{* *}$ & $-12.2^{* *}$ & $-5.4^{* *}$ & -0.1 \\
\hline Unskilled & $-3.0^{* *}$ & $0.5^{* *}$ & 0.2 & $-2.8^{* *}$ & 0.0 & $1.4^{* *}$ \\
\hline University degree & -2.6 & $3.0^{* *}$ & $3.6^{* *}$ & $-9.8^{* *}$ & $3.2^{* *}$ & $1.6^{* *}$ \\
\hline Foreign born & -1.4 & $-1.0^{*}$ & 0.6 & $-3.8^{* *}$ & -1.3 & $-1.3^{* *}$ \\
\hline Female foreign born & -2.1 & $-1.9^{*}$ & $-1.4^{* *}$ & -1.1 & 1.5 & -1.4 \\
\hline Children & $-2.1^{* *}$ & $0.7^{* *}$ & -0.1 & $-1.8^{\dagger}$ & 0.4 & 0.4 \\
\hline Children \& female & $-4.7^{* *}$ & -0.2 & $-2.2^{* *}$ & -1.7 & 1.1 & $-2.6^{* *}$ \\
\hline Minor job & $9.2^{* *}$ & 0.0 & $-0.4^{\dagger}$ & 3.9 & 1.5 & $-3.4^{* *}$ \\
\hline Spell starts in winter & $4.7^{* *}$ & $0.8^{* *}$ & 0.2 & $7.1^{* *}$ & $-1.0^{* *}$ & 0.2 \\
\hline \multicolumn{7}{|l|}{ Previous employment history } \\
\hline Part time & $-5.3^{* *}$ & $-0.9^{* *}$ & 0.0 & $5.0^{* *}$ & $-1.2^{\dagger}$ & $2.4^{* *}$ \\
\hline Lower/upper wage w $^{\ddagger}$ & $-2.7^{* *}$ & $1.1^{* *}$ & $-0.5^{* *}$ & $-5.2^{* *}$ & $1.6^{* *}$ & $4.5^{* *}$ \\
\hline Lower/upper wage \& female $^{\dagger}$ & 0.8 & -0.2 & $0.6^{*}$ & 2.2 & 0.7 & $-0.8^{*}$ \\
\hline Construction & $8.5^{* *}$ & $-1.2^{* *}$ & $-0.8^{* *}$ & $10.3^{* *}$ & $-1.9^{\dagger}$ & $-2.2^{* *}$ \\
\hline Trade and Food Ind. & $7.7^{* *}$ & $-0.6^{*}$ & -0.1 & $3.8^{* *}$ & 0.8 & $-2.0^{* *}$ \\
\hline Services/Public sector & $3.8^{* *}$ & $-0.5^{* *}$ & $0.6^{* *}$ & $-3.4^{* *}$ & $1.7^{* *}$ & $-0.5^{*}$ \\
\hline Previously recalled & $15.7^{* *}$ & $-1.7^{* *}$ & $-0.4^{*}$ & $14.8^{* *}$ & $-4.6^{* *}$ & 0.4 \\
\hline Previously unemployed & $1.3^{* *}$ & $1.0^{* *}$ & $-0.4^{* *}$ & $1.9^{* *}$ & -0.4 & 0.0 \\
\hline Large firm & $-2.7^{* *}$ & $-1.2^{* *}$ & 0.2 & $-5.9^{* *}$ & $-1.6^{* *}$ & $0.7^{*}$ \\
\hline BE 6-12 mths & $3.7^{* *}$ & 0.3 & 0.1 & $-2.7^{* *}$ & $2.2^{* *}$ & $-1.2^{* *}$ \\
\hline BE $12-18$ mths & -1.0 & 0.5 & 0.2 & $-9.7^{* *}$ & $2.5^{*}$ & $-1.5^{* *}$ \\
\hline BE 18-24 mths & -3.7 & 0.9 & $-1.1^{\dagger}$ & $-15.1^{* *}$ & $4.0^{* *}$ & $-2.9^{* *}$ \\
\hline $\mathrm{BE}>24 \mathrm{mths}$ & $-21.0^{* *}$ & $-1.7^{*}$ & $-1.9^{* *}$ & $-28.2^{* *}$ & 1.6 & $-4.7^{* *}$ \\
\hline
\end{tabular}


ALMP measure

Commuter

Regional characteristics

Unemployment rate (UR)

Change in UR 1995-2000

GDP per head

Change of GDP 1995-2000

Rate of business set ups

Share of long-term U

Avg. yrs of schooling

Placement counsellor per U

Share of $\mathrm{U}$ in $A L M P_{R}$

Share of $\mathrm{U}$ in $A L M P_{S}$

Driving time to higher level city

Child care places \& child

University present

Saisonal unemployment

Rural region

Urban region

West \& 2000

West \& 2000 \& female

West \& 2001

West \& 2001 \& female

East \& 2000

East \& 2000 \& female

East \& 2001

East \& 2001 \& female

East \& 2002

East \& 2002 \& female

\begin{tabular}{|c|c|c|c|c|c|}
\hline$-31.1^{* *}$ & $7.2^{* *}$ & $-2.0^{* *}$ & $-25.2^{* *}$ & $12.7^{* *}$ & $-1.8^{* *}$ \\
\hline$-4.6^{* *}$ & $0.3^{\dagger}$ & $5.6^{* *}$ & $-11.8^{* *}$ & $0.7^{\dagger}$ & $8.0^{* *}$ \\
\hline$-2.3^{*}$ & 0.6 & 0.0 & -0.5 & $-1.8^{*}$ & 1.0 \\
\hline$-1.5^{* *}$ & $0.5^{* *}$ & 0.2 & $-3.3^{* *}$ & $0.7^{*}$ & $0.7^{* *}$ \\
\hline-0.5 & -0.2 & 0.2 & -0.7 & 0.3 & $0.4^{*}$ \\
\hline $0.7^{* *}$ & 0.1 & $-0.2^{* *}$ & 0.3 & $-0.5^{* *}$ & $-0.2^{*}$ \\
\hline $1.1^{* *}$ & $-0.2^{\dagger}$ & 0.0 & -0.2 & 0.2 & $0.3^{\dagger}$ \\
\hline$-1.9^{* *}$ & $-0.4^{*}$ & 0.2 & $-3.2^{* *}$ & $0.7^{*}$ & $0.9^{* *}$ \\
\hline $1.8^{* *}$ & -0.2 & $-0.5^{* *}$ & 0.6 & -0.3 & $-0.4^{*}$ \\
\hline 0.2 & $-0.4^{*}$ & $0.4^{* *}$ & $-1.2^{*}$ & -0.2 & $1.6^{* *}$ \\
\hline 0.1 & $0.5^{* *}$ & -0.1 & -0.1 & $0.6^{\dagger}$ & -0.1 \\
\hline$-1.4^{* *}$ & $0.9^{* *}$ & 0.1 & $-1.5^{*}$ & $1.1^{* *}$ & 0.0 \\
\hline $0.8^{* *}$ & -0.2 & $-0.2^{\dagger}$ & -0.2 & 0.1 & 0.2 \\
\hline 0.3 & $-0.3^{\dagger}$ & $-0.4^{* *}$ & 0.4 & 0.4 & -0.1 \\
\hline$-2.6^{* *}$ & 0.1 & $0.4^{* *}$ & $-1.8^{* *}$ & -0.3 & $1.0^{* *}$ \\
\hline-0.2 & 0.2 & 0.1 & $-2.5^{\dagger}$ & $1.8^{\dagger}$ & 0.0 \\
\hline$-1.8^{* *}$ & 0.0 & 0.2 & $1.6^{\dagger}$ & $-1.4^{* *}$ & 0.2 \\
\hline-0.1 & $1.0^{* *}$ & $-0.9^{* *}$ & $1.6^{*}$ & -0.6 & -0.4 \\
\hline $8.6^{* *}$ & 0.5 & $1.4^{* *}$ & $9.9^{* *}$ & $-1.1^{\dagger}$ & $1.0^{*}$ \\
\hline 0.4 & 0.0 & 0.0 & 1.3 & -0.3 & $-1.0^{*}$ \\
\hline $2.5^{* *}$ & $1.2^{*}$ & 0.3 & 0.1 & 0.5 & 0.8 \\
\hline $2.0^{\dagger}$ & 0.2 & 0.5 & 1.7 & -0.8 & 0.0 \\
\hline$-3.8^{* *}$ & $2.0^{*}$ & $3.7^{* *}$ & $-7.8^{* *}$ & 2.3 & $11.3^{* *}$ \\
\hline$-6.5^{* *}$ & 0.0 & $-0.7^{*}$ & 1.6 & $-2.1^{\dagger}$ & $-2.7^{* *}$ \\
\hline-2.0 & 0.5 & $3.6^{* *}$ & $-5.4^{* *}$ & 1.7 & $6.8^{* *}$ \\
\hline$-6.0^{* *}$ & 0.3 & $-1.0^{* *}$ & -1.8 & -1.3 & $-1.5^{*}$ \\
\hline 0.1 & 0.0 & $2.6^{* *}$ & -2.3 & 1.5 & $3.1^{* *}$ \\
\hline$-6.6^{* *}$ & 0.0 & $-1.1^{* *}$ & -0.2 & 0.5 & $-1.5^{* *}$ \\
\hline
\end{tabular}

Note: Low wages refers to individuals with pre-unemployment daily gross wages of less than 60 euros. BE=Benefit entitlements; $\mathrm{ALMP}=$ Active labour market program with focus on regular $(\mathrm{R})$ or secondary (S) employment; U=Unemployment

‡: Refers to individuals with daily pre-unemployment wages in the lowest (highest) wage quartile for the low (higher) wage sample.

Significance levels : $\quad \dagger: 10 \% \quad *: 5 \% \quad * *: 1 \%$ 
This result probably reflects the stronger labour force attachment of unemployed people who are in minor employment. Individuals who commuted to their last job have lower local but higher non-local employment probabilities. This may capture both a higher propensity to migrate as well as a higher propensity to commute very long distances.

Western/eastern Germany Despite the strong economic differences between western and eastern Germany, conditional unemployment durations are surprisingly similar. The much higher level of unemployment in eastern Germany and the long average duration of unemployment thus have to be explained by the huge inflow into unemployment just after reunification and the fact that many of these displaced workers never found regular employment. For those entering unemployment between 2000 and 2002, differences between the conditional unemployment duration in eastern and western Germany are small and in many cases even disappear as we reach the end of the observation period. With regard to subsidized employment this is probably due to a reduction in the formally extensive public spending for subsidized employment in eastern Germany. Nevertheless, married men from eastern Germany with low pre-unemployment wages are still significantly more likely to end up in subsidized employment. The likelihood of exiting to local regular employment remains significantly lower for most unemployed people in eastern Germany than for unemployed people in western Germany, whereas migration tends to be more likely among the unemployed from eastern Germany. Individuals from eastern Germany experience strong pull factors from western Germany which tends to increase their migration probabilities compared to unemployed from western Germany for whom such pull factors are likely to be much weaker.

Supply and demand conditions As expected, deficient local labour demand as reflected in high and increasing unemployment levels, tends to reduce the probability of finding employment locally within one year among all groups, especially among married men with high earning capacities. Among single people with higher earning capacities, this prolonging effect on unemployment duration is partially offset by higher migration levels, while their married counterparts increasingly enter subsidized employment in regions with an excess supply of labour. For individuals with low earning capacities, such counteracting effects are even smaller or absent. As a consequence, deficient local labour demand tends to prolong the duration of 
unemployment. In the absence of cushioning subsidized employment, this effect is particularly strong among the locally immobile groups, namely married men and individuals with low earning capacities.

Economic performance The indicators that proxy for the local economic performance do not show any robust pattern across the different groups of unemployed. The only exception is the strong and positive effect of the setting up of new local businesses on the likelihood of finding local employment within one year for individuals with low earning capacities. One reason for this positive effect may be that new firms tend to offer precarious jobs which are a more relevant type of employment for individuals on the fringe of the labour market. Apart from this noteworthy effect, the effects of other local indicators of economic performance are negligible. We therefore conclude that local economic performance does not seem to be an important determinant of labour market outcomes for jobseekers in Germany, one explanation of which may be that due to central wage bargaining regional productivity levels as reflected in local GDP do not translate into behaviorally relevant interregional wage differences.

Social structure Indicators of the local social structure mainly confirm the theoretical notion that the social context affects job search behavior. As expected, a high share of long-term unemployment significantly prolongs the duration of unemployment as the strong decrease in local exits is only marginally offset by increasing exits to non-local and subsidized employment. A low average schooling level comes with similar but less strong effects. We conclude that a discouraging social context indeed prolongs unemployment, but that there is no evidence that overall search effort is reduced. At least for some individuals, migration and exits to subsidized employment offer an alternative to continued unemployment. 
Table 5: Marginal effects in pp on the conditional cumulative probability of exiting to local, subsidized or nonlocal employment, Married Men

\begin{tabular}{|c|c|c|c|c|c|c|}
\hline \multirow[b]{2}{*}{ Variable } & \multicolumn{3}{|c|}{ Low wage } & \multicolumn{3}{|c|}{ High wage } \\
\hline & local & subsidized & non-local & local & subsidized & non-local \\
\hline \multicolumn{7}{|c|}{ Individual characteristics } \\
\hline Age $<26$ & $10.2^{* *}$ & 0.0 & $0.8^{\dagger}$ & 1.9 & 0.1 & -0.2 \\
\hline Age $26-35$ & $2.1^{* *}$ & 0.5 & $0.5^{*}$ & $2.3^{* *}$ & -0.3 & -0.1 \\
\hline Age 46-56 & $-8.3^{* *}$ & $2.8^{* *}$ & $-0.8^{* *}$ & $-5.7^{* *}$ & 0.0 & 0.0 \\
\hline Age $>56$ & $-22.1^{* *}$ & 0.5 & $-2.2^{* *}$ & $-20.6^{* *}$ & $-5.6^{* *}$ & $-1.2^{* *}$ \\
\hline Unskilled & $-3.4^{* *}$ & $1.1^{* *}$ & 0.0 & $-1.5^{*}$ & $-1.5^{* *}$ & 0.1 \\
\hline University degree & $-7.0^{* *}$ & $3.6^{* *}$ & 0.1 & $-10.0^{* *}$ & $2.5^{* *}$ & 0.4 \\
\hline Foreign born & $-2.0^{* *}$ & $-1.5^{* *}$ & 0.3 & $-5.7^{* *}$ & $-2.8^{* *}$ & $0.8^{*}$ \\
\hline Children & -0.5 & 0.2 & -0.1 & -0.6 & 0.0 & -0.2 \\
\hline Minor job & $13.9^{* *}$ & -0.4 & -0.6 & $9.0^{* *}$ & 1.0 & $-2.9^{* *}$ \\
\hline Spell starts in winter & $10.0^{* *}$ & 0.4 & 0.2 & $11.3^{* *}$ & $-2.7^{* *}$ & 0.1 \\
\hline \multicolumn{7}{|c|}{ Previous employment history } \\
\hline Part time & $-4.6^{* *}$ & $-0.9^{*}$ & -0.4 & \multicolumn{3}{|c|}{$\mathrm{n} / \mathrm{a}$} \\
\hline Lower/upper wage w $^{\ddagger}$ & $-8.2^{* *}$ & $0.8^{*}$ & $-0.5^{* *}$ & $-5.7^{* *}$ & $2.8^{* *}$ & $2.7^{* *}$ \\
\hline Construction & $16.6^{* *}$ & $-1.8^{* *}$ & -0.3 & $16.0^{* *}$ & $-3.4^{* *}$ & $-2.8^{* *}$ \\
\hline Trade and Food Ind. & $12.0^{* *}$ & $-1.0^{*}$ & 0.2 & $6.5^{* *}$ & -0.2 & $-1.0^{* *}$ \\
\hline Services/Public sector & $6.9^{* *}$ & $-0.6^{\dagger}$ & $0.8^{* *}$ & -0.4 & $1.9^{* *}$ & -0.1 \\
\hline Recall & $12.3^{* *}$ & $-2.1^{* *}$ & -0.3 & $16.1^{* *}$ & $-5.5^{* *}$ & $-0.5^{\dagger}$ \\
\hline Unemployment & $1.8^{*}$ & $1.2^{* *}$ & 0.1 & $1.6^{\dagger}$ & -0.4 & 0.3 \\
\hline Large firm & $-7.1^{* *}$ & 0.5 & -0.4 & $-4.5^{* *}$ & $-1.9^{* *}$ & -0.2 \\
\hline BE 6-12 mths & $1.2^{\dagger}$ & $0.7^{*}$ & $-0.3^{\dagger}$ & $-1.3^{\dagger}$ & $1.7^{* *}$ & $-0.6^{* *}$ \\
\hline BE 12-18 mths & 1.2 & -0.5 & -0.2 & $-6.9^{* *}$ & $3.1^{* *}$ & $-1.3^{* *}$ \\
\hline BE 18-24 mths & -1.2 & 1.1 & -0.3 & $-9.0^{* *}$ & $2.3^{* *}$ & $-1.4^{* *}$ \\
\hline $\mathrm{BE}>24 \mathrm{mths}$ & $-8.9^{* *}$ & $-3.1^{* *}$ & $-1.4^{* *}$ & $-27.3^{* *}$ & 0.2 & $-3.1^{* *}$ \\
\hline ALMP measure & $-28.4^{* *}$ & $7.2^{* *}$ & $-1.8^{* *}$ & $-29.2^{* *}$ & $15.2^{* *}$ & $-1.8^{* *}$ \\
\hline Commuter & $-3.9^{* *}$ & -0.4 & $5.2^{* *}$ & $-13.4^{* *}$ & 0.4 & $8.9^{* *}$ \\
\hline
\end{tabular}


Regional characteristics

Unemployment rate (UR)

Change in UR 1995-2000

GDP per head

Change of GDP 1995-2000

Rate of business set ups

Share of long-term U

Avg. yrs of schooling

Placement counsellor per U

Share of $\mathrm{U}$ in $A L M P_{R}$

Share of $\mathrm{U}$ in $A L M P_{S}$

Driving time to higher level city

Child care places per child \& child

University present

Saisonal unemployment

Rural region

Urban region

West \& 2000

West \& 2001

East \& 2000

East \& 2001

East \& 2002

\begin{tabular}{lll|lll}
0.1 & $-1.3^{*}$ & 0.2 & $-4.5^{*}$ & 1.0 & -0.1 \\
$-1.3^{* *}$ & 0.1 & -0.1 & $-4.3^{* *}$ & $0.8^{*}$ & 0.1 \\
0.5 & 0.0 & -0.2 & -0.6 & -0.3 & 0.2 \\
0.5 & -0.1 & 0.1 & 0.4 & 0.4 & -0.2 \\
$1.3^{* *}$ & -0.2 & 0.0 & -0.3 & 0.2 & -0.1 \\
$-3.7^{* *}$ & $0.5^{\dagger}$ & -0.2 & $-3.0^{* *}$ & 0.3 & $0.7^{* *}$ \\
$-1.1^{*}$ & $-0.6^{*}$ & $-0.4^{* *}$ & 0.9 & -0.1 & -0.2 \\
$-1.8^{* *}$ & 0.2 & $0.3^{\dagger}$ & $-2.6^{* *}$ & $0.6^{\dagger}$ & $1.4^{* *}$ \\
0.5 & 0.1 & $-0.3^{* *}$ & 0.3 & 0.3 & $-0.5^{* *}$ \\
0.0 & $0.4^{\dagger}$ & -0.1 & 0.6 & $0.8^{*}$ & $-0.6^{* *}$ \\
$1.1^{* *}$ & 0.0 & $-0.2^{\dagger}$ & 0.6 & -0.2 & $-0.2^{*}$ \\
$0.8^{\dagger}$ & $-0.9^{* *}$ & $0.2^{\dagger}$ & 0.9 & -0.4 & 0.0 \\
$-2.3^{* *}$ & 0.2 & $0.4^{\dagger}$ & $-2.2^{* *}$ & -0.5 & 0.0 \\
$-3.2^{* *}$ & $3.1^{* *}$ & 0.0 & -2.5 & 0.4 & $1.5^{*}$ \\
-0.4 & 0.2 & 0.4 & $2.9^{* *}$ & $-1.3^{*}$ & $-0.4^{\dagger}$ \\
1.4 & 0.1 & $-0.4^{*}$ & -0.2 & -0.4 & $-0.6^{* *}$ \\
$13.5^{* *}$ & $-1.1^{\dagger}$ & $1.1^{* *}$ & $6.9^{* *}$ & $-1.6^{* *}$ & $0.9^{*}$ \\
$4.4^{* *}$ & $-1.3^{*}$ & 0.3 & $-1.9^{\dagger}$ & -0.3 & 0.4 \\
-3.3 & $6.3^{* *}$ & $1.5^{\dagger}$ & $-5.9^{*}$ & -0.8 & $8.6^{* *}$ \\
-0.8 & $3.4^{*}$ & $1.4^{\dagger}$ & $-4.9^{*}$ & -0.1 & $7.3^{* *}$ \\
$2.8^{* *}$ & $3.2^{* *}$ & $1.5^{*}$ & -2.9 & 1.0 & $4.1^{* *}$
\end{tabular}

Note: Low wages refers to individuals with pre-unemployment daily gross wages of less than 60 euros. $\mathrm{BE}=\mathrm{Benefit}$ entitlements;

$\mathrm{ALMP}=$ Active labour market program with focus on regular $(\mathrm{R})$ or secondary $(\mathrm{S})$ employment; $\mathrm{U}=\mathrm{Unemployment}$

$\ddagger$ : Refers to individuals with daily pre-unemployment wages in the lowest (highest) wage quartile for the low (higher) wage sample.

Significance levels : $\quad \dagger: 10 \% \quad *: 5 \% \quad * *: 1 \%$ 
Institutional organization According to our findings, the recent emphasis on job counseling that is, among other things, reflected in the increasing number of job counsellors per unemployed jobseeker, is unlikely to substantially contribute to a shortening of unemployment duration. This is because significant changes in the likelihood of the three exit types almost balance out for all sub-samples. In particular, individuals with higher earning capacities are more likely to migrate and to exit to subsidized employment while there are less local exits in regions with a higher ratio of job counsellors to unemployed jobseekers. This may suggest that additional human resources in job counselling speed up exits to migration and subsidized employment at the cost of local placement without resulting in a positive net effect on the duration of unemployment. Similarly, we also find that an extensive local availability of labour market programs accelerates exits to subsidized employment at the expense of exits to regular employment. Among single people, we mainly observe less local exits, while among married men with higher earning capacities, subsidized employment rather substitutes for non-local employment. There therefore seems to be a small regional locking-in effect of active labour market policies for married men, but not for single people. In a study for western Germany, Arntz (2005) only finds a minor regional locking-in-effect for women.

Structural indicators The type of region as well as the driving time to the next large city capture major differences in the availability of employment opportunities within a commuting range. As the type of available jobs may differ depending on the type of region, this may explain the heterogenous result pattern across sub-samples. Rural regions, for example, tend to increase the local job finding chances of individuals with higher earning capacities, but have the opposite effect on low wage earners. This may be due to a lack of unskilled service jobs in rural areas. Subsidized employment partially cushions these differences with increasing exit probabilities in rural regions among low earning married men and decreasing exit probabilities for individuals with higher pre-unemployment earnings. Moreover, apart from single people with high earning capacities, all other groups show higher local exit probabilities in remotely located regions. This may suggest that relatively immobile groups of unemployed lower their reservation wage in regions with a lack of accessible jobs and thus experience faster exits to local employment.

The presence of a university reduces local job-finding among all groups and increases migration probabilities among all but married men with low earning ca- 
pacities. These results are in line with the idea that students may exert additional congestion effects on the local labour market as students seek a minor job during their studies and often start their job search after graduation in the local area. Finally, somewhat unexpectedly, a higher level of day care places per child weakly accelerates local exits among married men, but not among single parents although single parents are somewhat less likely to leave a region with an extensive child care infrastructure. Thus, there is no evidence that the availability of public infrastructure strongly affects the duration of unemployment.

\section{Summary, Conclusions and Outlook}

In the light of recent labour market reforms, this paper explores the extent to which the unemployment compensation system, the local organization of job placement and regional policies determine the duration of unemployment in Germany. For this purpose we perform a comprehensive analysis of unemployment duration using the latest generation of administrative individual data and a broad set of regional aggregate data in the period 2000-2004. By distinguishing three exit states, local regular employment, non-local regular employment and subsidized employment we are able to disentangle the effects of individual and regional characteristics on these destination states. This is highly relevant because both individual and regional characteristics often have diverging effects on the three destination states. As a consequence, previous estimates may have been biased if non-local or subsidized employment have not been separated from exits to local employment.

Based on competing-risk Cox proportional hazard estimates, we generally obtain that individual characteristics and in particular an individual's work history strongly affect the duration of unemployment and the chosen destination state while the effect of regional factors such as the unemployment rate is often rather small. This is consistent with German and international evidence concerning the impact of regional labour market conditions on the duration of unemployment until exiting to a local or non-local job (Kettunen, 2003; Yankow, 2002; Arntz, 2005). Regional disparities thus appear to be much less important than usually considered by the German public and by German policy makers. Even between western and eastern Germany, the conditional unemployment duration is very similar. Therefore, our results suggest that regional policies may only be a supplementary means of improving labour market outcomes of unemployed individuals. 
Similarly, there is no evidence that public counselling efforts and ALMP have much of an shortening effect on the duration of unemployment. In the case of ALMP we even obtain slightly negative labour market outcomes:

- Previous ALMP participants often end up in ALMP again (ALMP-careers).

- Migration rates are lower in regions where extensive use is made of ALMP (regional locking-in-effect).

These results indicate that the recent restructuring efforts of public employment services are unlikely to bring about a substantial reduction in unemployment. Nonetheless, restructuring efforts may contribute to the increasing efficiency of public spending, an aspect that we do not analyze in our work. For this reason and given our econometric approach it is difficult to compare our results directly with international evaluation studies which are available for several countries, e.g. the UK (Blundell, Costa Dias, Meghir and Van Reenen, 2004) and the Netherlands (van den Berg and van den Klaauw, 2006).

We obtain a number of indications that the unemployment compensation and welfare system strongly affect individual labour market outcomes:

- Individuals with low pre-unemployment earnings and thus high income replacement rates have the lowest exit hazards to regular employment.

- Older individuals with extremely long UB entitlements basically never leave for regular employment as they use UB as a means of early retirement.

We therefore conclude that the reduction of UB entitlements and income replacement rates are likely to drastically shorten unemployment for certain groups. A strong effect of the unemployment compensation system on the duration of unemployment has already been observed in the past. Christensen (2005) shows that social benefit recipients with high reservation wages are unlikely to leave unemployment. Similarly, Fitzenberger and Wilke (2006b) find that unemployed people with lower former wages are much less likely to leave unemployment. Müller et al. (2007) evaluate a reform of the unemployment benefit system in 1997 which reduced entitlement length for unemployment benefits for older unemployed. They show that this reform was successful in drastically reducing inflow to unemployment and the duration of unemployment in the relevant group of unemployed. 
Although our approach is fairly comprehensive and includes new data, it still has several limitations. Alternative destination states such as leaving the labour force or retirement, for example, should be an important extension to our competing risk approach. Unfortunately, our data does not provide information on these exit states such that we leave this extension to future research. Moreover, the fact that we do not observe the true length of the unemployment duration may affect our results. In addition, our econometric approach faces the methodological difficulty that a certain share of our unemployed population has zero probability for an exit to regular employment. This is known as the mover - stayer problem in the literature (Abbring, 2002; Addison and Portugal 2003) and results in the defectiveness of the unemployment duration distribution. Our estimation results may therefore be biased, but as the degree of defectiveness is limited in our data, this problem may be of minor importance. Our model does not include random effects in order to account for individual unobserved heterogeneity. For this reason we left the baseline hazard nonparametric and do not draw attention to it because it is likely to be biased. Also the assumption of proportional hazard rates can be incorrect as Fitzenberger and Wilke (2006a and 2006b) have shown with similar data that this assumption is implausible for several regressors. A more flexible approach which allows the effect of the regressors on the conditional distribution of unemployment duration to vary over the quantiles and thus even crossing of the conditional hazard rates, may provide more detailed insights. The empirical analysis in this paper still provides many new insights and it raises several interesting research questions which are left for future research. 


\section{Appendix A - Summary Statistics by sub-samples}

\begin{tabular}{|c|c|c|c|c|}
\hline \multirow[b]{2}{*}{ Individual characteristics } & \multicolumn{2}{|l|}{ Singles } & \multicolumn{2}{|c|}{ Married Men } \\
\hline & Low Wage & Higher Wage & Low Wage & Higher Wage \\
\hline Female & 41.7 & 26.0 & \multicolumn{2}{|c|}{$\mathrm{n} / \mathrm{a}$} \\
\hline Age $<26$ & 41.4 & 21.2 & 4.4 & 2.5 \\
\hline Age $26-35$ & 27.4 & 39.1 & 23.5 & 24.6 \\
\hline Age $46-56$ & 10.5 & 12.0 & 30.6 & 28.5 \\
\hline Age $>56$ & 1.8 & 2.0 & 8.0 & 7.0 \\
\hline Unskilled & 52.2 & 30.5 & 45.9 & 32.4 \\
\hline University degree & 1.6 & 7.2 & 1.5 & 5.6 \\
\hline Foreign born & 6.2 & 5.3 & 16.9 & 12.4 \\
\hline Female foreign born & 2.2 & 1.1 & \multicolumn{2}{|c|}{$\mathrm{n} / \mathrm{a}$} \\
\hline Children & 21.2 & 18.0 & 63.1 & 66.7 \\
\hline Children \& female & 11.6 & 4.8 & \multicolumn{2}{|c|}{$\mathrm{n} / \mathrm{a}$} \\
\hline Minor job & 8.6 & 1.0 & 8.8 & 1.3 \\
\hline Spell starts in winter & 32.0 & 39.1 & 37.6 & 45.2 \\
\hline \multicolumn{5}{|l|}{ Previous employment history } \\
\hline Part time & 20.3 & 4.6 & \multicolumn{2}{|c|}{$\mathrm{n} / \mathrm{a}$} \\
\hline Lower/upper wage ${ }^{\ddagger}$ & 39.5 & 22.9 & 26.6 & 27.8 \\
\hline Lower/upper wage ${ }^{\ddagger} \&$ female & 18.6 & 6.7 & \multicolumn{2}{|c|}{$\mathrm{n} / \mathrm{a}$} \\
\hline Construction & 4.3 & 2.8 & 6.5 & 4.3 \\
\hline Trade and Food Ind. & 14.7 & 26.2 & 25.8 & 35.7 \\
\hline Services/Public sector & 44.2 & 33.8 & 38.2 & 29.0 \\
\hline Recall & 12.2 & 20.2 & 19.9 & 28.3 \\
\hline Unemployment & 61.9 & 64.9 & 74.9 & 66.8 \\
\hline Large firm & 7.0 & 10.3 & 5.1 & 7.0 \\
\hline BE 6-12 mths & 43.4 & 49.2 & 31.5 & 39.7 \\
\hline BE 12-18 mths & 1.1 & 2.0 & 3.4 & 4.5 \\
\hline BE 18-24 mths & 0.9 & 2.2 & 3.3 & 5.7 \\
\hline $\mathrm{BE}>24 \mathrm{mths}$ & 0.9 & 2.2 & 3.7 & 7.0 \\
\hline ALMP measure & 9.4 & 1.5 & 12.5 & 1.3 \\
\hline Commuter & 20.8 & 27.7 & 20.8 & 29.2 \\
\hline Number of unemployment spells & 74,724 & 28,168 & 28,018 & 23,620 \\
\hline
\end{tabular}

Note: All covariates are dummy variables. $\mathrm{BE}=$ Benefit entitlements; $\mathrm{ALMP}=$ Active labour market programs

Minor Job $=$ Job $<15$ hrs/week while unemployed at the beginning of unemployment

‡: Refers to individuals with daily pre-unemployment wages in the lowest (highest) wage quartile for the low (higher) wage sample. 


\section{References}

[1] Abbring, J. (2002). Stayers versus Defecting Movers: A Note on the Identification of Defective Duration Models, Economics Letters 74, 327-331.

[2] Addison, J.T. and Portugal, P. (2003). Unemployment Duration: Competing and Defective Risks, The Journal of Human Resources 38, 156-191.

[3] Arntz, M. (2005). The Geographical Mobility of Unemployed Workers. ZEW Discussion Paper No. 05-34. ZEW, Mannheim.

[4] Arntz, M., Wilke, R.A. (2007). An Application of Cartographic Area Interpolation to German Administrative Data, Allgemeines Statistisches Archiv, forthcoming.

[5] Arntz, M., Wilke, R.A., Winterhager, H. (2006). Regionenmatching im Rahmen der Evaluation der Experimentierklausel des $\S$ 6c SGB II: Methodische Vorgehensweise und Ergebnisse. ZEW Discussion Paper No. 06-61. ZEW, Mannheim.

[6] Blien, U. et al. (2004). Typisierung von Bezirken der Agenturen für arbeit. Zeitschrift für Arbeitsmarktforschung 2, 146-175.

[7] Blundell, R., Costa Dias, M., Meghir, C., Van Reenen, J. (2004) Evaluating the Employment Impact of a Mandatory Job Search Program. Journal of the European Economic Association 3, 1386-1417.

[8] Brown, S., Sessions, J.G. (1997). A Profile of UK Unemployment: Regional versus Demographic Influences. Regional Studies 34, 351-366.

[9] BA (Bundesagentur für Arbeit) (2002). Arbeitsmarkt 2002. Amtliche Nachrichten der Bundesagentur für Arbeit 2002. Nürnberg.

[10] BA (Bundesagentur für Arbeit) (2004). Arbeitsmarkt 2004. Amtliche Nachrichten der Bundesagentur für Arbeit 2004. Nürnberg.

[11] Carling, K., Edin, P.-A., Harkman, A., Holmlund, B. (1996). Unemployment Duration, Unemployment Benefits, and Labour Market Programs in Sweden. Journal of Public Economy 59, 313-334. 
[12] Cockx, B., Dejemeppe, M. (2005). Duration Dependence in the Exit Rate out of Unemployment in Belgium. Is it True or Spurious? Journal of Applied Econometrics 20, 1-23.

[13] Christensen, B. (2005). Reservationslöhne und Arbeitslosigkeitsdauer, Jahrbücher für Nationalökonomie und Statistik 225, 303-324.

[14] Damm, A.P. and M. Rosholm (2003). Employment Effects of Dispersal Policies on Refugee Immigrants, Part I: Theory. IZA Discussion Paper No. 924. IZA, Bonn.

[15] Fahrmeir, L., Lang, S., Wolff, J., Bender, S. (2003). Semiparametric Bayesian Time-Space Analysis of Unemployment Duration. Allgemeines Statistisches Archiv 87, 281-307.

[16] Fallick, B.C. (1992). Job Security and Job Search in More Than One Labour Market. Economic Inquiry 3, 742-745.

[17] Fitzenberger, B., Wilke R.A. (2004). Unemployment Durations in WestGermany Before and After the Reform of the Unemployment Compensation System During the 1980s. ZEW Discussion Paper No. 04-24. ZEW, Mannheim.

[18] Fitzenberger, B., Wilke, R.A. (2006a). Using Quantile Regression for Duration Analysis. Allgemeines Statistisches Archiv 90, 105-120.

[19] Fitzenberger, B., Wilke, R.A. (2006b) Censored Box Cox Quantile Regression for Unemployment Duration in Germany. Unpublished manuscript, ZEW, Mannheim.

[20] Folmer, H., van Dijk, J. (1988). Differences in Unemployment Duration: A Regional or a Personal Problem? Applied Economics 20, 1233-1251.

[21] Frederiksson, P. (1999). The Dynamics of Regional Labour Markets and Active Labour Market Policy: Swedish Evidence. Oxford Economic Papers 51, 623-648.

[22] Ghatak, S., Levine, P., Price, S. W. (1996). Migration Theories and Evidence: An Assessment Journal of Economic Surveys 10, 159-198.

[23] Haurin, D.R., Sridhar, K.S. (2003). The Impact of Local Unemployment Rates on Reservation Wages and the Duration of Search for a Job. Applied Economics 35, 1469-1476. 
[24] Hujer, R., Schneider, H. (1996). Institutionelle und strukturelle Determinanten der Arbeitslosigkeit in Westdeutschland: Eine mikroökonometrische Analyse mit Paneldaten. In: Bernhard Gahlen, Helmut Hesse, Hans Jürgen Ramser (Eds.) Arbeitslosigkeit und Möglichkeiten ihrer Überwindung, Schriften des Wirtschaftswissenschaftlichen Seminars Ottobeuren. Vol.25, Tübingen, 53-76.

[25] Hummel, E., Jacobebbinghaus, P., Kohlmann, A., Oertel, M., Wübbeke, C., Ziegerer, M. (2005). Stichprobe der Integrierten Erwerbsbiografien, *IEBS 1.0., Handbuch-Version 1.0.0 FDZ Datenreport No. 6/2005. Nrnberg.

[26] Hunt, J. (1995). The Effect of Unemployment Compensation on Unemployment Duration in Germany. Journal of Labour Economics 13, 88-120.

[27] Jacobi, L. and J. Kluve (2006). Before and after the Hartz Reforms: The Performance of Active Labour Market Policy in Germany. IZA discussion paper No. 2100. Bonn.

[28] Kemmerling, A. and O. Bruttel (2005). New Politics in German Labour Market Policy? The Implications of the Recent Hartz Reforms for the German Welfare State. WZB discussion paper No. 2005-101. WZB, Berlin.

[29] Kettunen, Juha (2002). Labour mobility of unemployed workers. Regional Science and Urban Economics 32, 359-380

[30] Kyyrä, T., Wilke, R.A. (2007). Reduction in the Long-Term Unemployment of the Elderly: A Success Story from Finland. Journal of the European Economic Association 5, forthcoming.

[31] Lalive, R., van Ours, J.C., Zweimüller, J. (2006). How Changes in Financial Incentives Affect the Duration of Unemployment. Review of Economic Studies, forthcoming.

[32] Lee, S., Wilke, R.A. (2005). Reform of Unemployment Compensation in Germany: A Nonparametric Bounds Analysis using Register Data. ZEW Discussion Paper No. 05-29. ZEW, Mannheim.

[33] Lindeboom, M., van Ours, J.C., Renes, G. (1994). Matching Employers and Workers: An Empirical Analysis on the Effectiveness of Search. Oxford Economic Papers 46, 45-67. 
[34] Lüdemann, E., Wilke R.A., Zhang, X. (2006). Censored Quantile Regressions and the Length of Unemployment Periods in West Germany. Empirical Economics 31, 1003-1024.

[35] Machin, S., Manning, A. (1999). The Causes and Consequences of Longterm Unemployment in Europe. In: Ashenfelter, O. and D. Card (eds.). Handbook of labour Economics Vol. 3C. Elsevier: Amsterdam.

[36] Martin, J.P., Grubb, D. (2001). What works and for whom: a review of OECD countries' experiences with active labour market policies. IFAU working paper No. 2001:14 IFAU, Uppsala.

[37] McCall, B.P., McCall, J.J. (1987). A Sequential Study of Migration and Job Search. Journal of Labour Economics 5, 452-476.

[38] Meyer, Bruce (1990). Unemployment Insurance and Unemployment Spells. Econometrica 58 (4), 757-783

[39] Mortensen, D.T. (1990). A structural model of unemployment insurance benefit effects on the incidence and duration of unemployment. In: Weiss, Y. and G. Fishelson (eds.). Advances in the Theory and Measurement of Unemployment. Macmillan: Hampshire.

[40] Müller, E., Wilke, R.A., Zahn, P. (2007). Beschäftigung und Arbeitslosigkeit älterer Arbeitsloser: Eine mikroökonometrische Evaluation der Arbeitsloseneldreform von 1997. Jahrbücher für Nationalökonomie und Statistik 227, forthcoming.

[41] OECD (2005). OECD Employment Outlook (2005). Paris.

[42] Petrongolo, B. (2001). Re-employment probabilities and returns to matching. Journal of Labour Economics 19, 716-741.

[43] Ridder, G., Tunali, I. (1999). Stratified partial likelihood estimation Journal of Econometrics 92, 193-232.

[44] Ritchie, H., Casebourne, J., Rick, J. (2005). Understanding workless people and communities: A literature review. IES Research Report No. 255. IES, Norwich.

[45] Roed, K., Zhang, T. (2003). Does Unemployment Compensation Affect Unemployment Duration? The Economic Journal 113, 190-206. 
[46] Rogerson, R., Shimer, R., Wright, R. (2005). Search-Theoretic Models of the Labour Market: A Survey. Journal of Economic Literature 43, 959-988.

[47] Salop, S.C. (1973). Systematic Job Search and Unemployment. Review of Economic Studies 41, 191-201.

[48] Steiner, V. (1990). Long-term unemployment, heterogeneity and state dependence - new microeconomic evidence on unemployment persistence. Austrian Economic Papers 17, 53-65.

[49] Steiner, V. (2001). Unemployment Persistence in the West German Labour Market: Negative Duration Dependence or Sorting? Oxford Bulletin of Economics and Statistics 63, 91-113.

[50] Thomas, J.M. (1996). On the Interpretation of Covariate Estimates in Independent Competing-Risks Models. Bulletin of Economic Research 48, 27-39.

[51] Thomas, J.M. (1998). The Role of Selective Job Search in UK Unemployment. The Economic Journal 108, 646-664.

[52] van den Berg, G.B., van den Klaauw, B. (2006). Counselling and Monitoring of Unemployed Workers: Theory and Evidence from a Controlled Social Experiment. International Economic Review 47, 895-936.

[53] Westerlund, O. (1998). Internal Migration in Sweden: The Effects of Mobility Grants and Regional Labour Market Conditions. Labour 12, 363-388.

[54] Yankow, J.J. (2002). The Geographic Mobility of Displaced Workers: Do Local Labour Market Conditions Matter? Furman University Discussion Paper Furman University, Greenville. 